\title{
Preparation and characterization of nanosized Pt/Au particles on $\mathrm{TiO}_{2}$-nanotubes
}

\author{
Shu-Hua Chien ${ }^{\text {a,b, }}{ }^{*}$, Yuh-Cherng Liou ${ }^{\text {a,b }}$, and Ming-Chih Kuo ${ }^{\text {a }}$

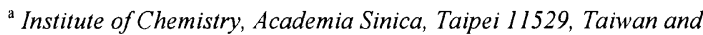 \\ ${ }^{\mathrm{b}}$ Department of Chemistry, National Taiwan University, Taipei 10764, Taiwan
}

\begin{abstract}
$\mathrm{TiO}_{2}$-nanotubes were prepared by hydrothermal treatment of $\mathrm{TiO}_{2}$ powders in concentrated $\mathrm{NaOH}$ solution at $110^{\circ} \mathrm{C}$ for 90 hours. The immobilization of $\mathrm{Pt}$ and $\mathrm{Au}$ was carried out by photochemical deposition method with $\mathrm{TiO}_{2}$-nanotubes suspending in an aqueous solution containing $\mathrm{H}_{2} \mathrm{PtCl}_{6} \cdot 6 \mathrm{H}_{2} \mathrm{O}$ or $\mathrm{HAuCl}_{4} \cdot 3 \mathrm{H}_{2} \mathrm{O}$. Transmission electron micrographs revealed that the diameter of the as-made TiO $2^{-}$ nanotube is about $10 \mathrm{~nm}$ with an inner diameter around $6 \mathrm{~nm}$. The nanotube shows layered structures similar to the carbon nanotubes. The layer spacing is about $0.88 \mathrm{~nm}$. Nanosized Pt $(\sim 2 \mathrm{~nm})$ and $\mathrm{Au}(\sim 10 \mathrm{~nm})$ particles were dispersed uniformly on the surface of the nanotubes. The BET surface area of the nanotube is $\sim 200 \mathrm{~m}^{2} / \mathrm{g}$ as estimated by $\mathrm{N}_{2}$ adsorption isotherm, that was not significantly affected after the immobilization of $\mathrm{Pt}$ or $\mathrm{Au}$. In-situ IR spectroscopic studies revealed that the $\mathrm{Pt} / \mathrm{TiO}_{2}$-nanotube is highly active for $\mathrm{CO}_{2}$ hydrogenation, while $\mathrm{Au} / \mathrm{TiO}_{2}$-nanotube exhibits pronounced activity for $\mathrm{CO}$ oxidation at room temperature. In general, $\mathrm{Pt} / \mathrm{TiO}_{2}$-nanotubes presents a relatively higher activity than $\mathrm{Au} / \mathrm{TiO}_{2}$-nanotubes, and the catalytic activities of $\mathrm{TiO}_{2}$ supported $\mathrm{Pt}$ and $\mathrm{Au}$ catalysts are significantly enhanced by the high surface area of $\mathrm{TiO}_{2}$-nanotube.
\end{abstract}

Keywords: $\mathrm{TiO}_{2}$-nanotubes; $\mathrm{Pt}, \mathrm{Au}$ nanocatalysts; In-situ IR; $\mathrm{CO}_{2}$ hydrogenation, $\mathrm{CO}$ oxidation

\section{Introduction}

Nanoscale materials have attracted great interest because of their novel properties, which are different from those of bulk materials. The materials with nanosized tubular structure include carbon, metal sulfides and metal oxides have been developed [1]. Among the nanostructured oxides, titania has been a focus of extensive research due to its chemical stability, large surface area, non-toxicity, and low production cost [2]. Titania nanotubes have been shown their potentials in many fields such as of photocatalysis [3], hydrogen sensing [4] and solar cells [5].

The methods to prepare titania nanotubes are mainly template synthesis [6,7] and hydrothermal method [8,9]. Titania nanotubes with diameters of 20-40 nm and inner diameters of 2.5-5 nm were made using anodic alumina as a template [7]. Smaller $\mathrm{TiO}_{2}$ nanotubes with diameters of about $9 \mathrm{~nm}$ and inner diameters of about $5 \mathrm{~nm}$ were reported using hydrothermal method via reaction of $\mathrm{TiO}_{2}$ and $\mathrm{NaOH}$ aqueous solution [9].

Titania is a well-known n-type semiconductor with high photocatalytic activity and widely used as a catalyst or catalyst supports [10]. Group VIII metals deposited titania are known to induce strong metal-support interactions (SMSI) which significantly affect on the chemisorptive properties and the catalytic reactions involving hydrogen and carbon monoxide [11]. The semiconductor-metal system could produce the Schotty barrier at the interface, which can serve as an efficient electron trap preventing electron recombination [12]. Bamwenda and coworkers [13] have reported a comparison of the photoassisted hydrogen production from a water-ethanol solution between $\mathrm{Au} / \mathrm{TiO}_{2}$ and $\mathrm{Pt} / \mathrm{TiO}_{2}$. The overall activity of $\mathrm{Au}$ samples was generally about $30 \%$ lower than that of $\mathrm{Pt}$ samples. Besides, titania supported metal catalysts prepared by photochemical deposition showed higher activities than those prepared by deposition-precipitation and impregnation $[13,14]$.

In our previous study $[14,15]$, nanosized Pt particles immobilized on $\mathrm{TiO}_{2}$ nanoparticle have been prepared by photochemical deposition and possess remarkably high catalytic activities for $\mathrm{CO}$ hydrogenation, $\mathrm{NO}$ reduction and $\mathrm{NO} / \mathrm{CO}$ reactions. We have prepared $\mathrm{TiO}_{2}$-nanotubes with high surface area following the hydrothermal method. Immobilized nanosized Pt particles on the surface of the nanotubes seem to result a potential catalyst for methane formation from $\mathrm{CO}_{2}$ [16]. In the present study, we converted the commercial $\mathrm{TiO}_{2}$ powders into $\mathrm{TiO}_{2-}$ nanotubes and immobilized $\mathrm{Pt}$ and $\mathrm{Au}$ particles on the nanotubes. The characterization of the as-made $\mathrm{TiO}_{2}-$ nanotubes and the supported $\mathrm{Pt}$ and $\mathrm{Au}$ catalysts were

* Corresponding author. Tel: +886-2-27898528; fax: +886-2-27831237 E-mail: chiensh@gate.sinica.edu.tw 
(a)

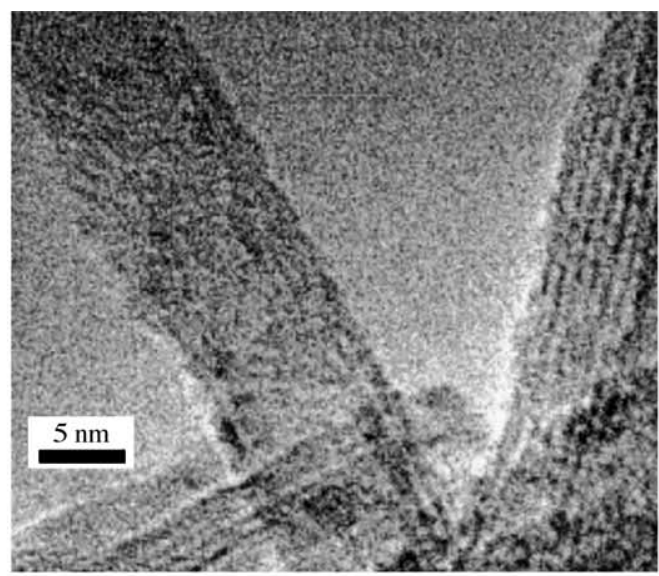

(b)

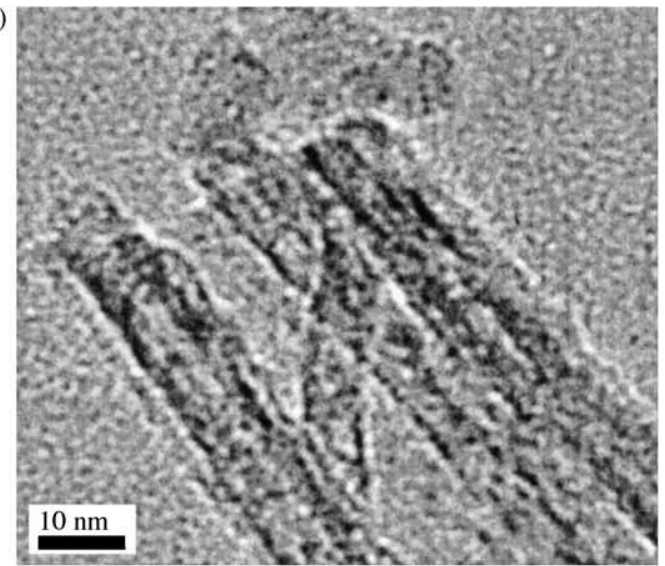

Fig. 1. TEM micrographs of (a) Pt/Tnt and (b) Au/Tnt.

carried out by TEM, XRD, EDS, XPS, $\mathrm{N}_{2}$ adsorption isotherm and $\mathrm{H}_{2} / \mathrm{CO}$ chemisorption. The catalytic activities for $\mathrm{CO}_{2}$ hydrogenation and $\mathrm{CO}$ oxidation were investigated by in-situ IR spectroscopy, or performed on a steady state flow-mode microreactor system.

\section{Experimental}

$\mathrm{TiO}_{2}$-nanotubes were prepared by hydrothermal method. In a typical procedure, $5 \mathrm{~g}$ of $\mathrm{TiO}_{2}$ powders, obtained from Merck (Art. 808) were dispersed in an aqueous solution of $10 \mathrm{M} \mathrm{NaOH}(180 \mathrm{ml})$ and then loaded into a Teflon-lined stainless steel autoclave. The autoclave was statically heated at $110^{\circ} \mathrm{C}$ for 90 hours. After the hydrothermal treatment, the resultant precipitate was separated by centrifugation and washing with diluted $\mathrm{HCl}$ solution, and repeated washing until $\mathrm{pH}<7$. The sample was then dried in an oven at $110^{\circ} \mathrm{C}$. After carefully grinding, $\mathrm{TiO}_{2}$-nanotubes were obtained.

The immobilization of $2 \mathrm{wt} \%$ of $\mathrm{Pt}$ and $\mathrm{Au}$ onto $\mathrm{TiO}_{2}$ nanotubes was carried out by photochemical deposition [14]. The $\mathrm{TiO}_{2}$-nanotubes $(2 \mathrm{~g})$ was dispersed in $200 \mathrm{ml}$ of deionized distilled water and then an appropriate amount of $\mathrm{H}_{2} \mathrm{PtCl}_{6} \cdot 6 \mathrm{H}_{2} \mathrm{O}$ or $\mathrm{HAuCl}_{4} \cdot 3 \mathrm{H}_{2} \mathrm{O}$ aqueous solution was added. The suspension was irradiated in a Rayonet Photochemical Reactor (model RPR-100) with wavelength of $3500 \AA$ lamps under stirring. After irradiation for $4 \mathrm{hr}$, the sample was washed twice with water and dried at $110^{\circ} \mathrm{C}$. Pt and $\mathrm{Au}$ supported on $\mathrm{TiO}_{2}$ powders were also prepared for comparison with those supported on $\mathrm{TiO}_{2}-$ nanotubes.

The morphology of the prepared catalyst was investigated by transmission electron microscopy (TEM). For getting better pictures, the sample specimens for TEM experiment were prepared by dispersing the powders in ethanol by ultrasonic treatment for several minutes, dropping onto a holey carbon film supported by a copper grid. The structural characterizations of the prepared $\mathrm{TiO}_{2}$ nanotubes and $\mathrm{Pt} / \mathrm{Au}$-immobilized catalysts were carried out by X-ray diffraction (XRD). The surface area and pore size distribution were obtained from nitrogen adsorption and desorption isotherm. $\mathrm{H}_{2}$ and $\mathrm{CO}$ chemisorption was employed to determine the metal dispersion of platinum and gold, respectively. In-situ infrared spectroscopic studies of catalytic properties were performed on a Bomem DA-8 FT-IR spectrometer.

The measurements of the catalytic activity for $\mathrm{CO}_{2}$ hydrogenation were carried out on a steady state flow-mode microreactor system operating at atmospheric pressure. 25 $\mathrm{mg}$ of the prepared catalyst was activated in hydrogen with a flow rate of $25 \mathrm{ml} / \mathrm{min}$ at $300^{\circ} \mathrm{C}$ for 2 hours. The mixed gas stream contained $25 \% \mathrm{CO}_{2}$ in $\mathrm{H}_{2}$ was introduced through the catalyst bed with a flow rate of $10 \mathrm{ml} / \mathrm{min}$. The exit gases were analyzed by an on-line Varian 3700 gas chromatograph with a GS-Q column (J\&W) heated at $40^{\circ} \mathrm{C}$ and a thermal conductivity detector (TCD). The TCD peak area was determined by Hewlett Packward 3395 integrator and calibrated with Matheson standard calibration gases.

\section{Results and Discussion}

$\mathrm{TiO}_{2}$ powders with particle size in the range of 200$500 \mathrm{~nm}$ have been hydrothermally transformed into $\mathrm{TiO}_{2-}$ nanotubes at $110^{\circ} \mathrm{C}$ for 90 hours. The resultant $\mathrm{TiO}_{2}$ nanotube, denoted as "Tnt" hereafter, was washed with diluted $\mathrm{HCl}$ solution. The results of EDS and XPS indicated that appreciable amount of sodium was still retained in the as-made $\mathrm{TiO}_{2}$-nanotubes after washing with $\mathrm{HCl}$. TEM micrographs reveal an open end of the nanotube, which is typical for the $\mathrm{TiO}_{2}$ nanotubes. The diameter is about $9-10 \mathrm{~nm}$ with the inner diameter of around $5-6 \mathrm{~nm}$. The tubular structure is similar to the carbon nanotube. The layer spacing is about $0.7 \mathrm{~nm}$. The wall of the nanotube consists of two to five layers. The number of layers on each side is usually not the same, indicating the nanotube is possibly scrolled [9]. Fig. 1 (a) and (b) show the TEM micrographs of Pt/Tnt and Au/Tnt samples. The tubular structure of $\mathrm{TiO}_{2}$ nanotube was sustained after the deposition of platinum and gold. The platinum and gold particles were found to be uniformly dispersed on the $\mathrm{TiO}_{2}$-nanotubes with the diameters of around $2 \mathrm{~nm}$ and $10 \mathrm{~nm}$, respectively 


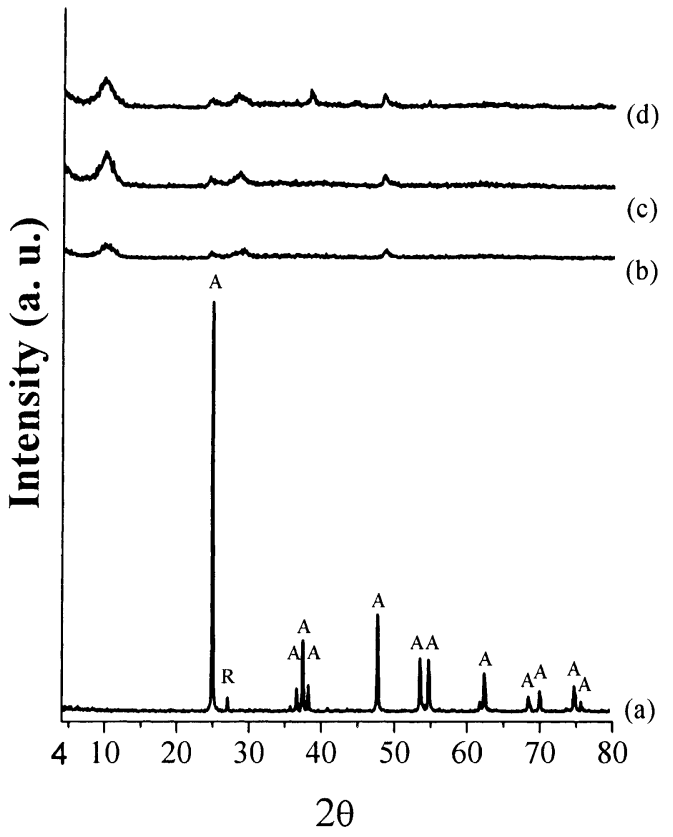

Fig. 2. XRD patterns of (a) $\mathrm{TiO}_{2}$, (b) Tnt, (c) Pt/Tnt and (d) Au/Tnt.

Fig. 2 shows the XRD patterns of the raw $\mathrm{TiO}_{2}$ powders, the as-prepared $\mathrm{TiO}_{2}$-nanotubes (Tnt), and $\mathrm{Pt}$ and $\mathrm{Au}$ immobilized Tnt. The raw $\mathrm{TiO}_{2}$ consists of major anatase phase and a trace of rutile phase. The characteristic peaks of the raw material were decreased with hydrothermal time and completely absent after 90 hours [16]. The results were consistent with the corresponding Raman and EPR spectra. XRD pattern of the Tnt sample shows new and weak diffraction peaks appeared at $2 \theta=$ $9.9^{\circ}, 24.5^{\circ}, 28.0^{\circ}$ and $48.5^{\circ}$, that are neither anatase nor rutile phase of $\mathrm{TiO}_{2}$. The tubular spacing of $0.88 \mathrm{~nm}$ was obtained from the corresponding d spacing at $2 \theta=9.9^{\circ}$ by the Bragg's law. The XRD patterns of nanotubes were still retained after the immobilization of $\mathrm{Pt}$ and $\mathrm{Au}$. The XRD peak of Pt was not found due to the peak broadening caused by the smaller Pt particles. The strongest peak (111) of Au was observed at $38.2^{\circ}$ on the pattern of $\mathrm{Au} / \mathrm{Tnt}$ (Fig. 2 (d)). The average particle size estimated from Scherrer equation is comparable to the TEM observation.

The $\mathrm{N}_{2}$ adsorption and desorption isotherm at $77 \mathrm{~K}$ of the $\mathrm{TiO}_{2}$-nanotubes is typically the type IV isotherm. The BET surface area of $\sim 200 \mathrm{~m}^{2} / \mathrm{g}$ was obtained, which is about 40 times greater than that of the raw $\mathrm{TiO}_{2}\left(\sim 5 \mathrm{~m}^{2} / \mathrm{g}\right)$. The average pore size of $0.87 \mathrm{~nm}$ derived from the Horvath-Kawazoe plot is similar to the tubular spacing obtained in XRD results. The surface areas of Pt/Tnt and $\mathrm{Au} / \mathrm{Tnt}$ are similar to that of Tnt, which indicates the deposition of nanosize Pt and Au particles do not cause significant variation in the surface area of nanotubes.

$\mathrm{H}_{2}$ chemisorption was employed to determine the metal dispersion of platinum on $\mathrm{TiO}_{2}$-nanotubes. The catalyst was activated in $\mathrm{H}_{2}$ flow at $200^{\circ} \mathrm{C}$ for 1 hour. The $\mathrm{Pt}$ dispersion $(\mathrm{H} / \mathrm{Pt})$ on $\mathrm{Tnt}$ and $\mathrm{TiO}_{2}$ particle are 0.63 and 0.41 , respectively. The corresponding particle size of

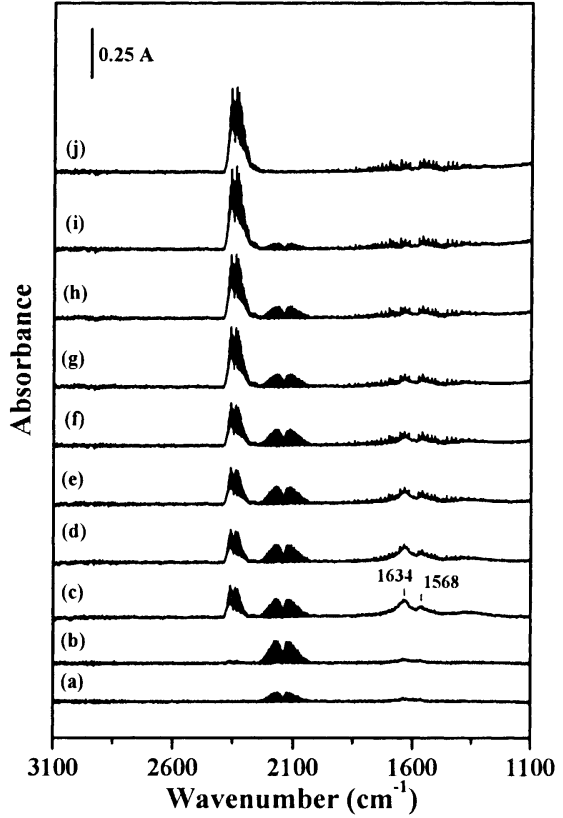

Fig. 3. In-situ FT-IR spectra of $\mathrm{CO}$ oxidation over Au/Tnt catalyst: (a) admission of 1 torr $\mathrm{CO}$, (b) admission of 10 torr $\mathrm{CO}$ and 40 torr $\mathrm{O}_{2}$, (c) static aging overnight, and then heating to (d) $50^{\circ} \mathrm{C}$, (e) $75^{\circ} \mathrm{C}$, (f) $100^{\circ} \mathrm{C}$, (g) $110^{\circ} \mathrm{C}$, (h) $125^{\circ} \mathrm{C}$, (i) $150^{\circ} \mathrm{C}$ and (i) $150^{\circ} \mathrm{C}$ for $10 \mathrm{~min}$

platinum is 1.8 and $2.8 \mathrm{~nm}$, respectively, which is consistent with the TEM results. The Au dispersion $(\mathrm{CO} / \mathrm{Au})$ on $\mathrm{TiO}_{2}$-nanotubes was measured by $\mathrm{CO}$ chemisorption. The catalyst was pretreated at $300^{\circ} \mathrm{C}$ in $\mathrm{O}_{2}$ flow for 1 hour and then in $\mathrm{H}_{2}$ flow for another hour. The $\mathrm{Au}$ dispersion is 0.11 , and the corresponding particle size of $\mathrm{Au}$ is $10.6 \mathrm{~nm}$.

As shown in our previous studies [16], $\mathrm{Pt} / \mathrm{TiO}{ }_{2}$ catalyst seemed to be a capable catalyst of absorbing $\mathrm{CO}_{2}$ and catalyzing the methane formation from $\mathrm{CO}_{2}$ through the intermediate $\mathrm{CO}$. The $\mathrm{Pt} / \mathrm{Tnt}$ catalyst directly converted $\mathrm{CO}_{2}$ to $\mathrm{CH}_{4}$ at a relatively low temperature of $100^{\circ} \mathrm{C}$. For $\mathrm{Au} / \mathrm{Tnt}$ and $\mathrm{Au} / \mathrm{TiO}_{2}$ catalysts, no methane or hydrocarbon products were found during heating in 60 torr $\mathrm{H}_{2}$.

Fig. 3 shows the in-situ IR spectra of $\mathrm{Au} / \mathrm{Tnt}$ catalyst. The catalyst was activated in $\mathrm{H}_{2}$ flow at $200^{\circ} \mathrm{C}$. After introduction of 1 torr $\mathrm{CO}$, besides the IR peaks of gaseous CO appeared at $2143 \mathrm{~cm}^{-1}$, the adsorbed carbonate species at 1634 and $1568 \mathrm{~cm}^{-1}$ were recorded. The admission of 10 torr $\mathrm{CO}$ and 40 torr $\mathrm{O}_{2}$ enhanced the intensity of gaseous $\mathrm{CO}$. After static aging overnight, the peak intensities of $\mathrm{CO}$ and the carbonate species were significantly decreased. $\mathrm{CO}_{2}$ at $2349 \mathrm{~cm}^{-1}$ was increased in the peak intensity. The IR cell was then heated at a constant rate of $2^{\circ} \mathrm{C} / \mathrm{min}$. The $\mathrm{CO}_{2}$ peak was increased with temperature as the digesting $\mathrm{CO}$ and carbonate species. The IR peak of gaseous $\mathrm{CO}$ was vanished at $150^{\circ} \mathrm{C}$ for $10 \mathrm{~min}$. The result indicated that the prepared $\mathrm{Au} / \mathrm{Tnt}$ catalyst is a capable catalyst for $\mathrm{CO}$ oxidation. Again, the $\mathrm{TiO}_{2}$ or Tnt supported Pt catalysts exhibit high catalytic activity for $\mathrm{CO}$ oxidation.

The $\mathrm{CO}_{2}$ hydrogenation over $\mathrm{Pt}$ and $\mathrm{Au}$ supported on $\mathrm{TiO}_{2}$-nanotubes and $\mathrm{TiO}_{2}$ particles were also performed in 


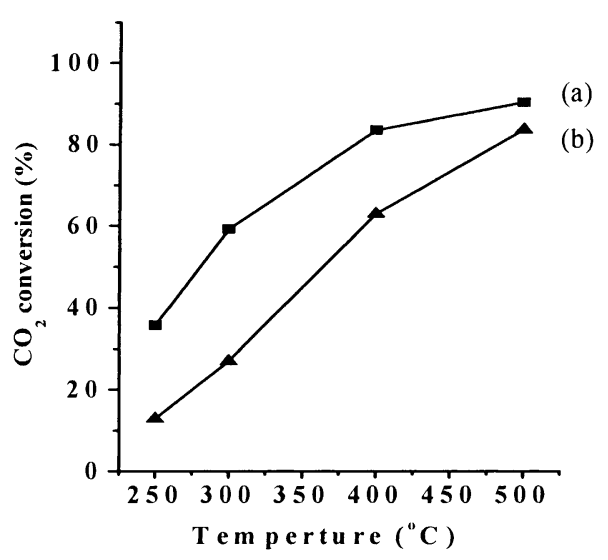

Fig. 4. Catalytic activity of $\mathrm{CO}_{2}$ hydrogenation over (a) Pt/Tnt and (b) $\mathrm{Pt} / \mathrm{TiO}_{2}$.

a steady state flow-mode microreactor system. For all experiment, the prepared catalyst was activated in hydrogen at $300^{\circ} \mathrm{C}$ for 2 hours and then the mixed gas stream contained $25 \% \mathrm{CO}_{2}$ in $\mathrm{H}_{2}$ was introduced through the catalyst bed. Fig. 4 shows the $\mathrm{CO}_{2}$ conversion over Pt/Tnt and $\mathrm{Pt} / \mathrm{TiO}_{2}$. It is noticeable that the catalytic activity of nanotubes-supported $\mathrm{Pt}$ catalyst is much higher than that of the $\mathrm{Pt} / \mathrm{TiO}_{2} . \quad \mathrm{CO}_{2}$ conversion increased with temperature and the primary product was $\mathrm{CH}_{3} \mathrm{OH}$ with a trace amount of $\mathrm{CH}_{4}$. The results of $\mathrm{CO}_{2}$ hydrogenation over $\mathrm{Au} / \mathrm{Tnt}$ and $\mathrm{Au} / \mathrm{TiO}_{2}$ catalysts, as can be seen in Fig. 5, also indicated that nanosized $\mathrm{Au}$ particles supported on $\mathrm{TiO}_{2}$-nanotubes presents a much higher catalytic activity than that supported on $\mathrm{TiO}_{2} . \mathrm{TiO}_{2}$-nanotubes supported $\mathrm{Pt}$ and $\mathrm{Au}$ catalysts possess much higher surface areas than the conventional $\mathrm{TiO}_{2}$ support and lead to higher catalytic activities. Pt/Tnt catalyst presents a relatively higher activity than $\mathrm{Au} / \mathrm{Tnt}$ catalyst. It was found that methane became to be the main product when the $\mathrm{H}_{2} / \mathrm{CO}_{2}$ ratio of the reactant stream was increased.

\section{Conclusions}

We have successfully prepared $\mathrm{TiO}_{2}$-nanotubes by hydrothermal conversion from the commercial $\mathrm{TiO}_{2}$ powders. Nanosized $\mathrm{Pt}(\sim 2 \mathrm{~nm})$ and $\mathrm{Au}(\sim 10 \mathrm{~nm})$ particles uniformly dispersed on the surface of $\mathrm{TiO}_{2}$-nanotubes by photochemical deposition. The $\mathrm{TiO}_{2}$-nanotubes revealed the diameter of $\sim 10 \mathrm{~nm}$ and the inner diameter of $\sim 6 \mathrm{~nm}$. It showed a layered structure similar to a carbon nanotube with a layer spacing of about $0.88 \mathrm{~nm}$. The $\mathrm{Pt}$ and $\mathrm{Au}$ immobilized $\mathrm{TiO}_{2}$-nanotubes have a large surface of $\sim 200 \mathrm{~m}^{2} / \mathrm{g}$. In-situ IR spectroscopic studies revealed that the $\mathrm{Pt} / \mathrm{TiO}_{2}$ nanotubes is highly active for $\mathrm{CO}_{2}$ hydrogenation. Although $\mathrm{TiO}_{2}$-nanotube-supported Au catalyst exhibits no activity for methane formation; it is active for $\mathrm{CO}$ oxidation at room temperature. $\mathrm{Pt} / \mathrm{Tnt}$ catalyst presents a relatively higher activity than $\mathrm{Au} / \mathrm{Tnt}$ catalyst. The catalytic activities of $\mathrm{TiO}_{2}$ supported Pt and Au catalysts were significantly enhanced by high surface area of $\mathrm{TiO}_{2}$-nanotubes.

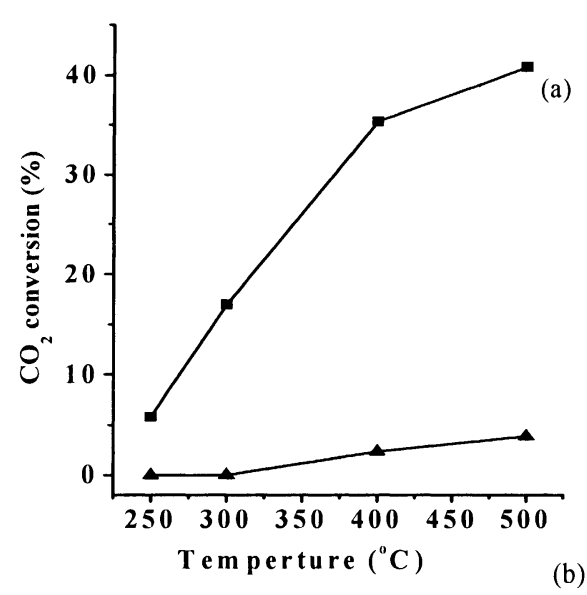

Fig. 5. Catalytic activity of $\mathrm{CO}_{2}$ hydrogenation over (a) $\mathrm{Au} / \mathrm{Tnt}$ and (b) $\mathrm{Au} / \mathrm{TiO}_{2}$.

\section{Acknowledgments}

We gratefully acknowledge financial supports from Academia Sinica and the National Science Council of the Republic of China.

\section{References}

[1] Y. Zhu, H. Li, Y. Koltypin, Y.R. Hacohen, A. Gedanken, Chem Commun. (2001) 2616.

[2] V.V. Ivanovskaya, A.N. Enyashin, A.L. Ivanovskii, Mendeleev Commun. 1 (2003) 1.

[3] M. Adachi, Y. Murata, M. Harada, S. Yoshikawa, Chem. Lett. 8 (2000) 942.

[4] O.K. Varghese, D. Gong, M. Paulose, K.G. Ong, C.A. Grimes, Sens. Actuators B 93 (2003) 338.

[5] S. Uchida, R. Chiba, M. Tomiha, N. Masaki, M. Shirai, Electrochemistry 70 (2002) 418.

[6] P. Hoyer, Langmuir 12 (1996) 1411.

[7] S.M. Liu, L.M. Gan, L.H. Liu, W.D. Zhang, H.C. Zeng, Chem. Mater. 14 (2002) 1391.

[8] T. Kasuga, M. Hiramatsu, A. Hoson, T. Sekino, K. Nihara, Langmuir 14 (1998) 3160

[9] Y.Q. Wang, G.Q. Hu, X.F. Duan, H.L. Sun, Q.K. Xue, Chem. Phys Lett. 365 (2002) 427.

[10] A. Fujishima, K. Honda, Nature 238 (1972) 37.

[11] J. M. Herrmann, J. Catal. 89 (1984) 404.

[12] A.L. Linsebigler, G. Lu, J.T. Yates, Jr. Chem. Rev. 95 (1995) 735.

[13] G.R. Bamwenda, S. Tsubota, T. Nakamura, M. Haruta, J. Photochem. Photobiol. A: Chem. 89 (1995) 177.

[14] S.H. Chien, K.N. Lu, C.T. Chen, Bull. Inst. Chem., Acad. Sin. 40 (1993) 37.

[15] S.H. Chien, M.C. Kuo, C.H. Lu, K.N. Lu, Catal. Today, 97 (2004) 121.

[16] S.H. Chien, M.C. Kuo, Y.C. Liou, Chem. Mater. submitted. 